International Journal of Instruction e-ISSN: 1308-1470 • www.e-iji.net
July $2019 \bullet$ Vol.12, No.3

p-ISSN: 1694-609X

pp. 17-34

Received: 01/11/2018

Revision: 01/03/2019

Accepted: 08/03/2019

OnlineFirst:24/04/2019

\title{
Instructional Mode: A Better Predictor of Performance Than Student Preferred Learning Styles
}

\author{
Jase Moussa-Inaty
}

College of Education, Zayed University, United Arab Emirates, jase.inaty@zu.ac.ae

\section{Fida Atallah}

Dr., College of Education, Zayed University, UAE, fida.atallah@zu.ac.ae

\section{Mark Causapin}

Dr., Concordia College Moorhead, Minnesota, USA, mcausapi@cord.edu

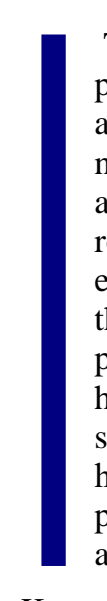

This study sought to investigate the link between preferred learning styles, performance, and cognitive load. After determining learning styles (visual or auditory), undergraduate students were assigned to three instructional formats, namely: Listen Only, Read Only, and Read + Listen. A pretest was administered to assess students' prior knowledge on lightning. During acquisition, students received instructions specific to the instructional format they were assigned to. For example, students in the Read Only group received written materials only while those in the Listen Only group received auditory materials only. The acquisition phase was followed by a posttest phase. Based on cognitive load theory, it was hypothesized that different instructional formats would result in differences in student performances. Two-way between-groups ANOVA results confirm the hypotheses, in that student's cognitive load was a better predictor of student performance than student learning styles. Educational implications and limitations are also discussed.

Keywords: cognitive load, learning styles, modes of instruction, learning, students

\section{INTRODUCTION}

Cognitive Load Theory (CLT) uses an information processing approach to cognition that is based on the human cognitive architecture. Based on CLT, instructional materials should be designed in such a way to reduce the learner's cognitive load and enhance learning performance (Sweller, 2010). The current study draws on CLT as a theoretical framework while relating it to the literature on learning styles. Since students have varying learning style preferences (e.g. visual or auditory) and may perform differently based on the instructional format they are presented with, this research calls for an investigation on preferred learning styles and student performances while also

Citation: Moussa-Inaty, J., Atallah, F., \& Causapin, M. (2019). Instructional Mode: A Better Predictor of Performance Than Student Preferred Learning Styles. International Journal of Instruction, 12(3), 17-34. https://doi.org/10.29333/iji.2019.1232a 
considering cognitive constraints that may be posed by varying instructional modes. It is hypothesized that although students may have a preferred learning style, cognitive load and conditions of learning matter more for instruction and learning. In other words, when students are presented with information that burdens the limitations of one's cognition, performance may be hindered even when preferred learning styles are taken into consideration.

\section{ISSUES WITH LEARNING STYLES}

Pashler, McDaniel, Rohrer, and Bjork (2008) describe learning styles as differences relative to the mode of instruction that is most effective for individuals. Orlich, Harder, Callahan, Tevisan, Brown, and Miller (2012) have defined learning styles as a "set of cognitive, affective and physiological traits that a learner exhibits as he or she interacts in the classroom environment and determines how he or she will solve problems" ( $p$. 351). Others have defined learning styles as a consistent way of functioning that may influence learning (Keefe, 1987). Given the various definitions of learning styles, Cassidy (2004) argues about the importance of an operational definition of learning styles to be able to utilize it for promoting effective learning, but cautions that this could be problematic.

In addition to issues with definition, a body of literature advocates that instructional designers should turn to learning style research in order to inform the design of learning materials (McLoughlin, 1999; Riding \& Grimley, 1999) despite the fact that there seems to be no adequate evidence to support incorporating learning style assessments into current educational practices (Pashler et al., 2008). McLoughlin (1999) for example, aimed to propose ways in which individual differences can be accommodated when designing self-instructional learning materials. Pashler et al. (2008) suggested that further research might be justified due to the lack of sound methodological studies related to learning styles. Similar findings are shared by Romanelli, Bird, and Ryan (2009) who conclude that there is limited research that correlates learning styles with educational outcomes. When reviewing the theory and application of learning styles, Romanelli et al. (2009) report on a range of views from advocates of matching teaching to learning styles to others who argue that mismatches between learning styles and teaching styles challenge students to improve their academic abilities. Regarding methodological issues, Romanelli et al. (2009) critique that the descriptors used in the scales that measure learning styles scales are more like measures of personality.

Kirshner and van Merrinëboer (2013) critically discuss what they call urban legends related to learning styles and education research. Kirshner and van Merrinëboer (2013) argue that there are three major problems with the learning style research. The first problem is that learning styles are conceptualized as dichotomous variables; for example either a person is visual or not visual, but the truth is, "most people do not fit in one particular style" (p. 173), and the information used to assign learners is often inadequate. The second problem relates to the measures being used to collect information about learners' learning styles. Self-report measures are most commonly used when determining students' learning styles, and according to Veenman, Prins, and Verheij (2003 as cited by Kirshner \& van Merrinëboer, 2013), the validity of self-report 
measures is questionable. The third problem according to Kirshner and van Merrinëboer (2013) relates to the actual number of learning styles. There are simply too many learning style combinations making it an unusable construct. More recently Kirshner (2017) argued that learning styles research receives little support from objective studies and studies do not satisfy the key criteria for scientific validity. The issue on selfreporting is also noted by Knoll, Otani, Skeel and Van Horn (2016) in that self-reporting is an ineffective predictor of the way people learn most effectively. Knoll et al. (2016) argue that what people often prefer is not necessarily what is best for them.

Some have argued for what is known as the Matching Hypothesis in that differences in learning styles exist and that teachers should teach different kinds of learners differently (e.g. Thakur, Vij, \& Shri, 2017). The link between learning styles and learning is also evident and has also been empirically investigated. For example, Rogowksy, Calhoun, and Tallal (2015) found no statistically significant relationship between the preference for a particular learning style and learning. Rogowksy et al. (2015) showed that learning style preference with college-educated adults had no impact on verbal comprehension aptitude (listening or reading) and learning based on mode of instruction (digital audiobook or e-text). A review of the literature on learning styles concluded that there isn't enough evidence to justify the use of learning styles assessments in educational practices (Pashler et al, 2009). However, the authors caution against generalizing the notion that all versions of learning styles are lacking in such benefits. They attribute their view to the lack of sound research methodology in studies conducted on learning styles.

As there are many kinds of learning style models (Coffield, et al., 2004; Felder \& Silverman, 1988), the current study chose to use the Visual-Auditory-Kinesthetic learning style model known as VAK because it is frequently used in learning environments (Akbulut \& Cardak, 2012; Gholami \& Bagher, 2013; Lujan \& DiCarlo, 2006; Ocepek, Bosnić, Nančovska Šerbec, \& Rugelj, 2013; Wehrwein, Lujan, \& DiCarlo, 2007) as a tool to help identify student's preferred learning styles that may then inform the design of instructional modes and materials. The VAK learning styles inventory provides a perspective on explaining student's preferred learning styles and includes items related to visual, auditory, and kinesthetic (Barbe, Swassing, Milone, 1979). However the popularity of VAK does not compensate for the problems inherit in the inventory itself as documented in the literature. It is described as a weak version of learning styles with no evidence of validity or reliability (Sharp et al. in 2008). The current study acknowledges the shortcomings of the VAK model and discusses the impact on the results of the study in the limitations section.

\section{COGNITIVE LOAD THEORY}

CLT offers a theoretical framework that allows for an understanding of how learners may optimize their learning experiences based on what is known of the human cognitive architecture. The human cognitive architecture indicates that working memory (WM) is limited in capacity (Miller, 1956), meaning that our WM can only hold a limited amount of information at one given time. Our WM is also limited in duration (Peterson \& Peterson, 1959). Long-term memory on the other hand can hold endless amounts of 
information without any mental burden (De Groot, 1965). This is due to schema automation. When no schemas for a specific topic or concept have been constructed and (novice) learners are faced with new tasks, WM may be heavily burdened. When appropriate schemas are constructed and become automated, this facilitates transfer of performance of an acquired knowledge (Paas, Tuovinen, Tabbers, \&Van Gerven, 2003). But as stressed by Ayres (2006), the key is to focus on the relationship between WM and long-term memory and how instructional materials interact with this cognitive architecture. CLT has identified principles for structuring instruction in ways that recognize and consider the human cognitive architecture (Sweller, 2004, 2010) and has recently made a distinction between generic-cognitive knowledge that does not require explicit instruction and domain- specific knowledge that can be explicitly taught (Sweller, 2015). Accordingly, CLT offer a number of strategies that reduce cognitive overload. Of particular relevance to this study is modality effect, which has been applied in various areas such as language learning and multimedia (Ari, Flores, Inan, Cheon, Crooks, Paniukov, \& Kurucay, 2014; Chen \& Wu, 2015; Kozan, Erçetin, \& Richardson, 2015; Moussa-Inaty \& Atallah, 2012; Moussa-Inaty, Ayres, \& Sweller, 2012; Sarikhani \& Zare, 2015).

When considering ways to measure cognitive load, Paas and Van Merriënboer's (1994) proposed model suggests that cognitive load can be determined by measuring mental load, mental effort, and the performance of a learner. Subjective dimensions of measuring cognitive load have been used and validated on several occasions. With subjective ratings, learners are required to engage in self-assessment and answer questions on items based on scales such as self-reported invested mental effort or difficulty of the material being acquired or used in a study (Paas, et al., 2003). Some studies have questioned the timing at which subjective ratings should be collected during an investigation showing that when it is delayed, ratings may impact the results (Schmeck, Opfermann, Van Gog, Paas, \& Leutner, 2015). Though different techniques have been used to capture physiological variables (Antonenko, Paas, Grabner, \& van Gog, 2010; Chen, Epps, Ruiz, \& Chen, 2011), and with the possibility of the measure being bias, subjective measures remain the most commonly used form of measuring cognitive load effort. Accordingly, cognitive load was measured after the participants completed the pretest, acquisition and posttest. Participants were presented with a 9point Likert scale ranging from 1 (very easy) to 9 (very difficult) and asked to circle one number that best described how easy or difficult the acquisition and posttests were for them.

\section{Modality Effect}

A number of studies have identified the modality effect with diagrams written, and spoken text. For example, Moussa-Inaty et al. (2012) investigated the consequences of simultaneously reading and listening when learning English as a foreign language in which students were either exposed to written English only (single modality) or written and spoken English (dual modality). The findings from this study indicated that participants exposed to reading alone performed better on listening tests than participants exposed to a reading and listening condition despite the reading alone 
participants having had less experience with listening. The dual modality condition increased extraneous cognitive load through unnecessary processing of redundant material, diverting WM resources away from learning. Recently, Morrison et al. (2015) showed no significant differences in achievement test scores when diagrams where paired with lengthy text materials.

Research has found that dual information modes (e.g. auditory and visual) can also have a positive effect on learning. The positive learning effect of a dual mode is called the modality effect. Frick (1984) for example showed that when learning materials were presented in a visual modality and some in an auditory modality rather than all in a single modality, more items would be recalled. Since the identification of the modality effect, much research has been conducted to find the specific conditions under which a mixed mode of learning can be most effective. Penney (1989) demonstrated that presenting material in a dual mode (using both visual and auditory form) actually increased WM capacity. This was also supported by Mousavi, Low, and Sweller (1995) who concluded that using a dual-modality approach in multimedia learning may actually increase WM resources by triggering both the auditory and visual WM slave systems identified by Baddeley (1992), rather than just one of them. Significant work on the modality effect can be seen through the work of Moreno and Mayer (1999). Moreno and Mayer's (1999) mixed-modality presentations showed to be superior to the most integrated text and visual presentations and it was argued "when learners can concurrently hold words in auditory WM and pictures in visual WM, they are better able to devote attentional resources to building connections between them" (p. 366). Moreno and Mayer (2002) also later demonstrated no cognitive overload was caused when verbal and nonverbal auditory inputs were presented together. Others such as, Kalyuga, Chandler and Sweller (1999), Brünken, Plass and Leutner (2004), and Leahy and Sweller (2011) also support the dual modality principle in their investigations. Recent investigations have shown that the length and complexity of audio and visual materials will also demonstrate a modality effect where shorter audio-visual information is superior to longer visual only information (Leahy \& Sweller, 2016). Other recent efforts have shown that elementary school children may benefit when pictures are presented but for enhanced learning any added text presented should be in spoken rather than written form (Herrlinger, Höffler, Opfermann, \& Leutner, 2017). Herrlinger et al. (2017) note that if learners read by themselves by looking at pictures, this may indeed exceed working memory capacity and create a cognitive overload. In short, the dual modality approach to learning has gained much credibility as it has been demonstrated to have a positive influence on learning. It should be noted though that the modality effect is also contingent upon learner expertise level (Kalyuga, Ayres, Chandler, \& Sweller, 2003).

\section{Cognitive Load Theory and Learning Styles}

Both cognitive and learning styles have often been used interchangeably and can be used to predict effective modes of instruction. Researchers have often shown a link between working memory, cognitive styles, and academic performance (e.g. Alloway, Banner, \& Smith, 2010; Grimley, Michael, \& Banner, 2008; Riding, Grimley, Dahraei, \& Banner, 
2003) and highlight that the interplay between working memory and cognitive styles may be used to further develop necessary interventions that may support learning. Though the same cognitive architecture is true for all learners, when it comes to learning styles, it can be argued that different learning styles (e.g. visual and auditory) may or may not impose cognitive overload depending on how materials are presented. Still, a body of research recognizes learning styles as important factors for student learning while overlooking possible cognitive overloads. Tseng, Chu, Hwang, and Tsai (2008) proposed courses for learners based on their learning styles and difficulty of the learning content. Felder and Silverman (1988) argued that the teaching environment of learners needed to match the learner's preference of a specific learning style for enhanced performance. Graf, Liu, Kinshuk, Chen, and Yang (2009) showed that when educational adaptive systems incorporate both learning styles and cognitive traits, this had a positive impact on student learning. More recently, Hsieh, Jang, Hwang, and Chen (2011) developed adaptive mobile systems based on students learning styles, results supporting that matching learning styles of students to the appropriate teaching styles can improve student learning. In a systematic review of the literature Coffield, Moseley, Hall, and Ecclestone (2004) identified several theories that focused on different aspects of learning styles. Others have also has indicated that learners attain higher test scores when learning materials match learners preferred learning styles (Pillay \& Wilss, 1996). Dobson (2010) also demonstrated a link between learning style preferences, gender and course performance. Recently Koć-Januchta, Höffler, Thoma, Prechtl, and Leutner (2017) provided evidence that when classified according to their visualizer-verbalizer cognitive style, people differ in their learning behavior in terms of using pictorial and verbal information while learning. This study highlights the existence of the visualverbal cognitive style and its influence on learning behaviour. Ezzeldin (2017) also examined the impact of using graphic organizers in development of achievement, reduction of cognitive load associated with solving algorithm problems in analytical chemistry and favoured learning styles among secondary school students. The results indicated statistically significant differences in cognitive load associated with solving algorithm problems between different types of learning styles such as convergent learning style and adaptive learning style.

Even though a range of studies have linked learning styles with performance, cognitive constraints that may cause cognitive overloads, have not been investigated and are overlooked. Based on CLT, this body of research could imply that when learners are presented with materials that correspond to the learners preferred learning style, cognitive load or mental effort ratings should be lower when compared to learners who are presented with materials that do not correspond to their learning styles.

\section{METHOD}

\section{Research Aim}

There is an agreed concern among researchers because individual differences in cognitive and learning styles have often been criticized for conceptual confusion and questionable reliability and validity (Peterson, Rayner, \& Armstrong, 2009). Still, there seems to be little to no attempts to address these concerns. The current study attempts to 
address some of these concerns and draws on CLT as a theoretical framework while also relating it to the literature on students varying learning style preferences. Accordingly, the current study argues that cognitive constraints are important factors that may determine student performance regardless of student's preferred learning styles. Therefore, this research calls for an investigation on preferred learning styles and student performances while also considering cognitive constraints that may be posed by varying instructional modes. In short, while considering student's learning styles, this study will explore which mode of instruction allows for enhanced performance with the least amount of burden on WM. It was hypothesized that cognitive load would have a nontrivial relationship with student performance regardless of learning style preference. The study utilized a quantitative approach in order to test the hypothesis. Six experimental conditions were formed (see Table 2).

\section{Participants}

Ethical approval and participant consent was sought prior to the start of the study. The study was conducted at Zayed University, which is a federal institution in the United Arab Emirates (UAE) that uses English as the medium of instruction. Though Zayed University has both male and female students, students are separated based on gender with a separate campus for the male students and a separate campus for the female students. The study sample consisted of ninety-four female students only who were enrolled in undergraduate Education courses, although the participants were not all Education major students. The participants were native Arabic speakers aged between 19 and 30 with a mean age of 21 years.

\section{Experimental Materials}

There were two parts to the current study. For the first part, the VAK learning styles inventory was used in order to measure participant's learning styles. As there are many kinds of learning style models (Coffield, et al., 2004; Felder \& Silverman, 1988), the current study chose to use the VAK learning style model for the first part of the study because it is frequently used in learning environments (Akbulut \& Cardak, 2012; Gholami \& Bagher, 2013; Lujan \& DiCarlo, 2006; Ocepek, Bosnić, Nančovska Šerbec, \& Rugelj, 2013; Wehrwein, Lujan, \& DiCarlo, 2007) as a tool to help identify student's preferred learning styles that may then inform the design of instructional modes and materials. The VAK learning styles inventory provides a perspective on explaining student's preferred learning styles and includes items related to visual, auditory, and kinesthetic (Barbe, Swassing, \& Milone, 1979).

Regarding the second part, there were three phases: a pretest, acquisition, and posttest. The experimental materials used were carefully designed. Analysis of the text used for the three phases was reviewed by two evaluators for content validity and test reliability purposes. The evaluators are experts in science education and active researchers with a doctorate degree in the field of education

The participants learnt novel information about lightning, through a structured lesson. The topic on lightning was chosen because students in the UAE are not typically exposed to lightning neither through books, other educational resources, nor in reality 
given the extremely hot weather throughout the entire year. The lesson was designed and presented in three instructional formats: Listen Only - materials presented in auditory form only; Read Only - materials presented in written form only; and Read and Listen materials presented in both auditory and written forms simultaneously. The pretest assessed the participant's prior knowledge on lightning and included a variety of short answer questions; namely: explain lightning, name the various types of lighting, explain how lightning is caused, and then provide at least one safety tip when lightning strikes. The questions on the pretest were then used as the basis for the acquisition and posttest content. The tasks were printed on A4 white paper using black font.

During acquisition, the lesson on lighting included instructions and vocabulary and their translations from English to Arabic. Translations were included to ensure all participants clearly understood the materials and that the language did not pose a hindrance on student learning and performance. If participants were not able to understand the materials because of the language in which the materials were presented, then this would have burdened their working memory-hence the need for translations. The acquisition also included three lessons related to the topic on lightning and each lesson was followed by an acquisition test. Acquisition 1 (A1) was titled "What is lightning?" and was divided into two parts. Part A defined lightning and part B described three types of lightning. This lesson was followed by a 4-item multiple-choice acquisition test. Acquisition 2 (A2) was titled "What causes lightning?" This lesson was followed by a 4item comprehension acquisition test. Acquisition 3 (A3) was titled "Lightning safety tips" and was followed by a 4-item multiple-choice acquisition test. The acquisition phase was followed by a posttest phase that included three tests (T1, T2, \& T3) related to the lessons learnt on lightning during acquisition. For example, some questions on T2 included, "Explain what may happen if you are next to a tree during a thunderstorm? and "Compare and contrast two types of lighting." For T3 a scenario was presented about a boy who was at his family's farm in the desert. Then something occurs that leaves the boy having to make a decision in order to stay safe. Participants had to justify their responses. Table 1 summarizes the distribution of the pretest, acquisition, and posttest among the participants in the varying groups.

Table 1

Distribution of the Pretest, Acquisition, and Posttest Among the Groups

\begin{tabular}{ll}
\hline Pretest & Short answer questions \\
\hline \multirow{3}{*}{ Acquisition } & 1. Acquisition 1 (A1): a. Lesson; b. Test \\
& 2. Acquisition 2 (A2): a. Lesson; b. Test \\
& 3. Acquisition 3 (A3): a. Lesson; b. Test \\
\hline \multirow{3}{*}{ Posttest } & 1. Test 1 (T1): Fill in the blanks \\
& 2. Test 2 (T2): Comprehension questions \\
& 3. Test 3 (T3): Knowledge application
\end{tabular}

\section{Procedure}

This study sought to investigate the relationship between various instructional formats on student's learning, while considering CLT and students preferred learning styles. Participants preferred learning styles (auditory or visual) were determined using the 
VAK learning style inventory. For internal validity purposes, it was necessary for the researchers to identify the learning style of the participants prior to the study because the placement of participants into the varying groups depended on the preferred learning style. This process did not bias their participation because the instructions provided during the completion of the survey (VAK inventory) was specific to identifying preferred learning styles and was not specific cognitive overload or mental effort. Once learning styles were identified, the researchers assigned the participants to the groups that corresponded to their preferred learning styles - visual or auditory. For purposes of the study any students who were identified as kinesthetic learners were not included in the study. Accordingly, random assignment into the groups was not possible. Since there were three modes of instructions for each of the groups (visual and auditory) a further breakdown resulted in a total of six varying groups: Listen Only Visual group (LoV), Read Only Visual group (RoV), Read + Listen Visual group (RLV), Listen Only Auditory group (LoA), Read Only Auditory group (RoA), and Read + Listen Auditory group (RLA). Table 2 shows the distribution of the groups and number of students per group.

Table 2

Distribution of Participants

\begin{tabular}{lll}
\hline & Auditory & Visual \\
\hline Read Only & 15 & 15 \\
Listen Only & 16 & 15 \\
Read \& Listen & 16 & 17 \\
\hline
\end{tabular}

During acquisition, three lessons on lightning were presented (A1, A2, \& A3). Students in the Listen Only group learnt about lightning through auditory materials only, those in the Read Only group learnt about lightning through written materials only, whereas students in the Read + Listen group learnt about lightning through both auditory and written materials simultaneously. After the completion of the acquisition, three posttests (T1, T2, \& T3) were administered using pen and paper. All three tests included questions that assessed for either retention and/or transfer. T1 (retention) consisted of a paragraph with empty spaces and students were required to fill in the blank with a correct word. T2 (retention and transfer) included five comprehension questions and students were required to write short answers on the answer sheet provided. T3 (retention and transfer) was a scenario developed by the researchers that required making a decision related to lightning safety tips. All testing tasks were related to the lessons during acquisition. Participants in all the groups received the same testing material and the same amount of time to complete the tasks during the pretest, acquisition and posttest. Instructions on how to complete the tasks were provided in either written or auditory form depending on the group the participants were assigned to. As subjective measures remain the most commonly used form of measuring cognitive load effort (see Antonenko, Paas, Grabner, \& van Gog, 2010; Chen, Epps, Ruiz, \& Chen, 2011), all students completed a mental effort rating scale based on a 9-point Likert scale after the completion of the pretest, acquisition and posttest in order to measure cognitive load. The timings are in line with recent recommendations as discussed earlier (see Schmeck, Opfermann, Van Gog, Pass, \& Leutner, 2015). 
For the pretest, acquisition and posttest, a specific time varying from a minimum of 12 seconds to a maximum of 1 minute and 20 seconds was allocated. The complete experiment ran for a total of approximately 60 consecutive minutes on the same day. It should be noted throughout this study the same female researcher ran the experiment for the six varying groups over a period of three days and following the specified procedure as previously indicated. The experiment was conducted at the same time of day.

\section{Scoring}

Participants were required to complete seven tasks (pretest, A1, A2, A3, T1, T2, and T3) without access to the learning materials in the acquisition phase and the three in the test phase. The same scoring procedure was completed for all six groups. The maximum score possible on each task was 20 (pretest); 20 (A1); 20 (A2); 20 (A3); 30 (T1); 25 (T2) and 5 (T3). A further scoring breakdown for each of the three tests (T1, T2, and T3) shows; 2 points for each correct answer on T1with a maximum total score of 30; 5 points for each correct answer on T2 with a maximum score of 25; and 5 points for a correct answer (more than one correct answer was possible).

\section{FINDINGS}

In the initial data analysis, the means and standard deviations of scores were calculated for each group during the three phases of the experiment and for each of the various tasks within the experimental phases as shown in Table 3. Initial findings suggest that the $\mathrm{RoV}$ group outperformed the other groups during the acquisition phase, while the RLV group outperformed all other groups during the testing phase. The group that performed the worst during the testing phase was the LoV group. The LoA group was outperformed by all other groups during the acquisition phase and also had the highest mental effort rating mean.

Table 3

Means and Standard Deviations of Scores for the six experimental groups (RoA, RoV, LoA, LoV, RLA, and RLV)

\begin{tabular}{|c|c|c|c|c|c|c|c|c|c|}
\hline & & \multicolumn{2}{|c|}{$\begin{array}{l}\text { Pretest Score (total of } \\
20 \text { points) }\end{array}$} & \multicolumn{2}{|c|}{$\begin{array}{l}\text { Acquisition Total } \\
\text { Score (total of } 60 \text { ) } \\
\text { points }\end{array}$} & \multicolumn{2}{|c|}{$\begin{array}{l}\text { Test Total Score (total } \\
\text { of } 60 \text { points) }\end{array}$} & \multicolumn{2}{|c|}{ Mental Effort Rating } \\
\hline & & Mean & $\begin{array}{l}\text { Standard } \\
\text { Deviation }\end{array}$ & Mean & $\begin{array}{l}\text { Standard } \\
\text { Deviation }\end{array}$ & Mean & $\begin{array}{l}\text { Standard } \\
\text { Deviation }\end{array}$ & Mean & $\begin{array}{l}\text { Standard } \\
\text { Deviation }\end{array}$ \\
\hline \multirow[t]{2}{*}{$\mathrm{R}$} & $\mathrm{A}$ & 2.4 & 3.9 & 38.5 & 10.8 & 32.9 & 8.4 & 5 & 1 \\
\hline & $\mathrm{V}$ & 2.7 & 3.7 & 43.4 & 7.8 & 31.7 & 11.9 & 5 & 2 \\
\hline \multirow[t]{2}{*}{$\bar{L}$} & $\mathrm{~A}$ & 3.4 & 4.8 & 35.6 & 13.4 & 30.2 & 12.4 & 6 & 2 \\
\hline & $\mathrm{V}$ & 2.9 & 3.2 & 41.1 & 13.0 & 26.1 & 16.0 & 5 & 2 \\
\hline \multirow[t]{2}{*}{$\overline{\mathrm{RL}}$} & $\mathrm{A}$ & 4.6 & 5.1 & 41.7 & 11.6 & 33.4 & 14.0 & 5 & 2 \\
\hline & $\mathrm{V}$ & 2.6 & 5.0 & 39.6 & 10.5 & 37.4 & 9.8 & 5 & 2 \\
\hline
\end{tabular}


Table 4

Two-Way Analysis of Variance of Lesson 1 Test Scores by Instructional Mode and Learning Style

\begin{tabular}{llll}
\hline Source & $\mathrm{df}$ & $\mathrm{F}$ & $\mathrm{p}$ \\
\hline Corrected Model & 5 & 3.204 & 0.011 \\
\hline Intercept & 1 & 992.235 & 0.000 \\
\hline Instructional Mode & 2 & 4.437 & 0.015 \\
\hline Learning Style & 1 & 5.787 & 0.018 \\
\hline Instructional Mode x Learning Style & 2 & 0.587 & 0.558 \\
\hline Error & 88 & & \\
\hline Total & 94 & & \\
\hline Corrected Total & 93 & & \\
\hline
\end{tabular}

Table 5

Tukey Pairwise Comparisons Between the Experimental Groups

\begin{tabular}{lllll}
\hline Instructional Mode (A) & Instructional Mode (B) & $\begin{array}{l}\text { Mean Difference } \\
(\mathrm{A}-\mathrm{B})\end{array}$ & Std. Error & $p$ \\
\hline Read Only & Listen Only & 3.801 & 1.2551 & 0.009 \\
& Read + Listen & 1.924 & 1.2363 & 0.270 \\
\hline Listen Only & Read Only & -3.801 & 1.2551 & 0.009 \\
& Read + Listen & -1.877 & 1.2258 & 0.281 \\
\hline Read + Listen & Read Only & -1.924 & 1.2363 & 0.270 \\
& Listen Only & 1.877 & 1.2258 & 0.281 \\
\hline
\end{tabular}

Table 6

Learning Style Comparison

\begin{tabular}{lllll}
\hline \multirow{2}{*}{ Learning Style } & \multirow{2}{*}{ Mean } & \multirow{2}{*}{ Std. Error } & \multicolumn{2}{c}{$95 \%$ Confidence Interval } \\
\cline { 4 - 5 } & & & Lower Bound & Upper Bound \\
\hline Auditory & 14.722 & 0.715 & 13.301 & 16.143 \\
Visual & 17.157 & 0.716 & 15.734 & 18.580 \\
\hline
\end{tabular}

As for Test 3 after the Acquisition stage (Fill-in the blanks test), Table 7 shows that the instructional mode had effects on scores $(p$-value $=0.029)$. The mean scores of students in the Read + Listen was higher than in the Listen Only (see Table 8).

Table 7

Two-Way Analysis of Variance of Test 3 after the Acquisition stage (Fill-in the blanks test) Test Scores by Instructional Mode and Learning Style

\begin{tabular}{|c|c|c|c|}
\hline Source & df & $\mathrm{F}$ & $p$ \\
\hline Corrected Model & 5 & 1.856 & 0.110 \\
\hline Intercept & 1 & 376.734 & 0.000 \\
\hline Instructional Mode & 2 & 3.696 & 0.029 \\
\hline Learning Style & 1 & 0.041 & 0.841 \\
\hline Instructional Mode x Learning Style & 2 & 0.998 & 0.373 \\
\hline Error & 88 & & \\
\hline Total & 94 & & \\
\hline Corrected Total & 93 & & \\
\hline
\end{tabular}


Table 8

Tukey Pairwise Comparisons Between the Experimental Groups

\begin{tabular}{lllllll}
\hline $\begin{array}{l}\text { Instructional Mode } \\
\text { (A) }\end{array}$ & $\begin{array}{l}\text { Instructional Mode } \\
\text { (B) }\end{array}$ & $\begin{array}{l}\text { Mean Difference } \\
\text { (A - B })\end{array}$ & Std. Error & $p$ & \multicolumn{2}{c}{ 95\% Confidence Interval } \\
\hline Read Only & Listen Only & 3.178 & 1.7798 & 0.180 & -1.065 & 7.422 \\
& Read + Listen & -1.406 & 1.7531 & 0.703 & -5.585 & 2.773 \\
\hline Listen Only & Read Only & -3.178 & 1.7798 & 0.180 & -7.422 & 1.065 \\
& Read + Listen & -4.585 & 1.7382 & 0.026 & -8.728 & -0.441 \\
\hline Read + Listen & Read Only & 1.406 & 1.7531 & 0.703 & -2.773 & 5.585 \\
\hline
\end{tabular}

\section{DISCUSSIONS}

The current study attempted to investigate the impact of students' learning styles and instructional modes on student performance from a cognitive load perspective. Even though there are mixed views on the importance of learning styles when aligning them to instruction (Romanelli, et al., 2009), the results of the current study mirror and support the literature (e.g. Kirshner \& van Merrinëboer, 2013) in that instructional designers do not need to necessarily take students' preferred learning styles into account in order to facilitate learning. WM constraints should form the basis for instructional design particularly when acquiring novel information (Sweller, 2015). The study also supports previous work on redundancy and the modality effect (see Moussa-Inaty et al., 2012) in that reading showed to be more beneficial than listening. Participants who were required to listen only in order to complete tasks were outperformed by all other groups; those who were required to read only or read and listen. This is mainly due to the transient nature of listening, which causes a heavy burden on WM. These results further stress the importance of considering the presentation of written text when learning new materials as opposed to auditory materials, regardless of student's preferred learning styles.

The literature presented in this paper has linked learning styles and learning performance (e.g. Koć-Januchta, et al. 2017; Ezzeldin, 2017) highlighting the existence of cognitive styles and their influence on learning behavior. The cognitive overload caused by the varying instructional modes showed to be a better predictor of learning than preferred learning styles specifically if learners learning preference was either visual or auditory. Though further studies with both male and female participants included and a broader range of preferred learning styles may be needed, this study showed that at least under some circumstances the mode in which materials are being presented to the learners is a better predictor of student performance and cognitive overload. The study can therefore confirm that there was no significant interaction effect. The students' cognitive WM constraints and the outcome of effective instructional modes play a more significant role in student performance than preferred learning styles. In short, no matter what learning styles student's preferred, the instructional mode that burdened the students cognitive load showed to hinder student performance.

\section{Implications of the Study}

Educators will encounter different student learning style preferences, but should that be a guide to determining how to best design or present learning materials? Issues with learning style research are to be taken into account when trying to understand how leaners learn more effectively (see Kirshner 2017; Knoll, et al. 2016). Based on the 
results of the study, educators and instructional designers should consider factors related to the limitations of the WM. In other words, cognitive constraints are better predictors than learning styles when it comes to determining how materials should be presented for enhanced performance. At the institutional level, understanding the effective modes of instruction that take into considerations cognitive constraints may assist in creating flexible instructional strategies that allow for improved performance and learning. In line with the literature (e.g. Brünken, Plass \& Leutner, 2004; Herrlinger et al., 2017; Kalyuga, et al.1999; Leahy \& Sweller, 2016; Moreno \& Mayer, 2002; Moussa-Inaty et al., 2012, Moussa-Inaty, Causapin, Groombridge, 2018) cognitive load theory principles, when understood, can translate into appropriate learning environments, which will enable learners to achieve improved performance. As far as practical implications, the results of this study highlight that the design of materials for learners should take into account considerations of mental constraints, rather than considerations of learners' preferred learning styles. In fact, regardless of student's preferred learning style (particularly visual or auditory), students will perform poorly on tasks if tasks require high mental effort and if WM is burdened.

\section{Limitations and Recommended Future Studies}

The results of this study did not contradict the authors' initial hypothesis, which was based on the current literature on cognitive load theory, that there would be no significant correlation between student-preferred learning style, performance, and mental effort ratings. The results showed that different instructional formats resulted in differences in student performances. Nevertheless, it should be noted that the study was gender biased. Still, from a CLT perspective, if males were also included in this study similar results are likely to show since males and females have the same human cognitive architecture. Also, there are two areas in the study methodology that could be strengthened in future iterations of this research. First, the instrument to assess studentpreferred learning styles should be changed to one that has already been used and tested on university students. In this study, the VAK learning style model was chosen because it has been used frequently in other studies (see Akbulut \& Cardak, 2012; Gholami \& Bagher, 2013; Lujan \& DiCarlo, 2006; Ocepek, Bosnić, Nančovska Šerbec, \& Rugelj, 2013; Wehrwein, Lujan, \& DiCarlo, 2007). Second, the assignment of students into each group (Listen Only, Read Only, and the Read + Listen) should be completely random. This way, the study will be truly experimental and not a quasi-experiment, which would make the statistical conclusions more meaningful. In addition, the lack of normal distributions as demonstrated in the results may have been due to a ceiling effect-yet another potential limitation. Finally, another limitation relates to the sample size. Future studies may call on a larger sample size. A larger sample of participants was invited to take part in the study, but the failure of several students to attend resulted in a smaller sample size. This limitation may have been avoided by running a power analysis prior to the start of the study.

\section{REFERENCES}

Akbulut, Y., \& Cardak, C. S. (2012). Adaptive educational hypermedia accommodating learning styles: A content analysis of publications from 2000 to 2011. Computers \& Education, 58(2), 835-842. doi:10.1016/j.compedu.2011.10.008 
Antonenko, P., Paas, F., Grabner, R., \& van Gog, T. (2010). Using electroencephalography to measure cognitive load. Educational Psychology Review, 22(4), 425-438. doi:10.1007/s10648-010-9130-y

Ari, F., Flores, R., Inan, F. A., Cheon, J., Crooks, S. M., Paniukov, D., \& Kurucay, M. (2014). The effects of verbally redundant information on student learning: An instance of reverse redundancy. Computers \& Education, 76, 199-204. doi:10.1016/j.compedu.2014.04.002

Ayres, P. (2006). Using subjective measures to detect variations of intrinsic cognitive load within problems. Learning and Instruction, 16(5), 389-400.

Baddeley, A. D. (1992). Working memory. Science, 255, 556-559.

Barbe, W., Swassing, R., \& Milone, M. (1979). Teaching through modality strengths: Concepts and Practices. Columbus, OH: Zaner-Bloser, Inc.

Brünken, R., Plass, J. L., \& Leutner, D. (2004). Assessment of cognitive load in multimedia learning with dual-task methodology: Auditory load and modality effects. Instructional Science, 32, 115-132. doi:10.1023/b:truc.0000021812.96911.c5

Cassidy, S. (2004). Learning styles: An overview of theories, models and measures. Educational Psychology, 24(4), 419 - 444.

Chen, S., Epps, J., Ruiz, N., \& Chen, F. (2011). Eye activity as a measure of human mental effort in HCI. Proceedings of the 15th International Conference on Intelligent User Interfaces - IUI '11. doi:10.1145/1943403.1943454

Chen, C. M., \& Wu, C. H. (2015). Effects of different video lecture types on sustained attention, emotion, cognitive load, and learning performance. Computers \& Education, $80,108-121$.

Coffield, F., Moseley, D., Hall, E., \& Ecclestone, K. (2004). Learning styles and pedagogy in post-16 learning: A systematic and critical review. London, UK: Learning and Skills Research Centre.

Conover, W. J., \& Iman, R. L. (1981). Rank transformations as a bridge between parametric and nonparametric statistics. The American Statistician, 35(3), 124-129.

De Groot, A. (1965). Thought and choice in chess. The Hague, Netherlands: Mouton.

Dobson, J. L. (2010). A comparison between learning style preferences and sex, status, and course performance. Advances in Physiology Education, 34(4), 197-204.

Ezzeldin, S. M. (2017). The effectiveness of using graphic organizers in development of achievement, reduction of cognitive load associated with solving algorithm problems in analytical chemistry and favored learning styles among female secondary school students in Saudi Arabia. International Journal for Research in Education, 41(2), 77 124. 
Felder, R. M., \& Silverman, L. K. (1988). Learning and teaching styles in engineering education. Engineering Education, 78(7), 674-681.

Frick, R. W. (1984). Using both an auditory and a visual short-term store to increase digit span. Memory and Cognition, 12, 507-514.

Gholami, S., \& Bagheri, M. S. (2013). Relationship between VAK learning styles and problem solving styles regarding gender and students' fields of study. Journal of Language Teaching and Research, 4(4), 700-706.

Graf, S., Liu, T.C., Kinshuk, Chen, N.S., \& Yang, S. J. H. (2009). Learning styles and cognitive traits - Their relationship and its benefits in web-based educational systems. Computers in Human Behavior, 25(6), 1280-1289. doi:10.1016/j.chb.2009.06.005

Herrlinger, S., Höffler, T. N., Opfermann, M., \& Leutner, D. (2017). When do pictures help learning from expository text? Multimedia and modality effects in primary schools. Research in Science Education, 47(3), 685-704.

Hsieh, S.W., Jang, Y.R., Hwang, G.J., \& Chen, N.S. (2011). Effects of teaching and learning styles on students' reflection levels for ubiquitous learning. Computers \& Education, 57(1), 1194-1201. doi:10.1016/j.compedu.2011.01.004

Kalyuga, S., Chandler, P., \& Sweller, J. (1999). Managing split-attention and redundancy in mulitimedia instruction. Applied Cognitive Psychology, 13, 351-371. doi:10.1002/(SICI)1099-0720(199908)13:4<351::AID-ACP589>3.0.CO;2-6

Kalyuga, S., Chandler, P., \& Sweller. J. (2000). Incorporating learner experience into the design of multimedia instruction. Journal of Educational Psychology, 92, 126-136. doi:10.1037/0022-0663.92.1.126

Kalyuga, S., Ayres, P., Chandler, P., \& Sweller, J. (2003). The Expertise Reversal Effect. Educational Psychologist, 38(1), 23-31. doi:10.1207/s15326985ep3801_4

Keefe, J. W. (1987). Learning Style Theory and Practice. National Association of Secondary School Principals, 1904 Association Dr., Reston, VA 22091.

Kirschner, P. A. (2017). Stop propagating the learning styles myth. Computers \& Education, 106, 166-171.

Kirshner, P., \& van Merrinëboer, J. (2013). Do learners really know best? Urban legends in education. Educational Psychologist, 48(3), 169-183.

Knoll, A. R., Otani, H., Skeel, R. L., \& Van Horn, K. R. (2017). Learning style, judgements of learning, and learning of verbal and visual information. British Journal of Psychology, 108(3), 544-563.

Koć-Januchta, M., Höffler, T., Thoma, G. B., Prechtl, H., \& Leutner, D. (2017). Visualizers versus verbalizers: Effects of cognitive style on learning with texts and pictures-An eye-tracking study. Computers in Human Behavior, 68, 170-179. 
Kozan, K., Erçetin, G., \& Richardson, J. C. (2015). Input modality and working memory: Effects on second language text comprehension in a multimedia learning environment. System, 55, 63-73. doi:10.1016/j.system.2015.09.001

Leahy, W., \& Sweller, J. (2011). Cognitive load theory, modality of presentation and the transient information effect. Applied Cognitive Psychology, 25(6), 943-951. doi:10.1002/acp.1787

Leahy, W., \& Sweller, J. (2016). Cognitive load theory and the effects of transient information on the modality effect. Instructional Science, 44(1),107-123.

Lujan, H. L., \& DiCarlo, S. E. (2006). First-year medical students prefer multiple learning styles. Advances in Physiology Education, 30(1), 13-16.

McLoughlin, C. (1999). The implications of the research literature on learning styles for the design of instructional material. Australasian Journal of Educational Technology, 15(3), 222-241.

Miller, G. A. (1956). The magical number seven, plus or minus two: Some limits on our capacity for processing information. Psychological Review, 63, 81-97. doi:10.1037/0033-295x.101.2.343

Moreno, R., \& Mayer, R. E. (1999). Multimedia-supported metaphors for meaning making in mathematics. Cognition and Instruction, 17(3), 215-248. doi:10.1207/s1532690xci1703_1

Moreno, R., \& Mayer, R. (2002). Verbal redundancy in multimedia learning: When reading helps listening. Journal of Educational Psychology, 94, 156-163.

Morrison, J., Watson, G. S., \& Morrison, G. R. (2015). Exploring the redundancy effect in print-based instruction containing representations. British Journal of Educational Technology, 46(2), 423-436. doi:10.1111/bjet.12140

Mousavi, S. Y., Low, R., \& Sweller, J. (1995). Reducing cognitive load by mixing auditory and visual presentation modes. Journal of Educational Psychology, 87(2), 319-334. doi:10.1037/0022-0663.87.2.319

Moussa-Inaty, J. \& Atallah, F. (2012). Multimedia use in higher education in the UAE: A cognitive load theory perspective. Journal of Educational Multimedia and Hypermedia, 21(2), 127-142.

Moussa-Inaty, J., Causapin, M., \& Groombridge, T. (2018). Does language really matter when solving mathematical word problems in a second language? A cognitive load perspective. Educational Studies, 1-21. DOI: 10.1080/03055698.2018.1516629

Moussa-Inaty, J., Ayres, P., \& Sweller, J. (2012). Improving listening skills in English as a foreign language by reading rather than listening: A cognitive load perspective. Applied Cognitive Psychology, 26(3), 391-402. doi:10.1002/acp.1840 
Ocepek, U., Bosnić, Z., Nančovska Šerbec, I., \& Rugelj, J. (2013). Exploring the relation between learning style models and preferred multimedia types. Computers \& Education, 69, 343-355. doi:10.1016/j.compedu.2013.07.029

Orlich, D., Harder, R., Callahan, R., Trevisan, M., \& Brown, A. (2012). Teaching strategies: A guide to effective instruction. Cengage Learning.

Paas, F. (1992). Training strategies for attaining transfer of problem-solving skill in statistics: A cognitive-load approach. Journal of Educational Psychology, 84, 429-434. doi:0.1037/0022-0663.84.4.429

Paas, F., \& Van Merriënboer, J. G. (1994). Instructional control of cognitive load in the training of complex cognitive tasks. Educational Psychology Review, 6(4), 351-371. doi:10.1007/bf02213420

Paas, F., Tuovinen, J., Tabbers, H. K., \& Van Gerven, P.W.M. (2003). Cognitive load measurement as a means to advance cognitive load theory. Educational Psychologist, 38, 63-71. doi:10.1207/s15326985ep3801_8

Pashler, H., McDaniel, M., Rohrer, D., \& Bjork, R. (2008). Learning styles: Concepts and evidence. Psychological Science in the Public Interest, 9(3), 105-119. doi:10.1111/j.1539-6053.2009.01038.x

Penney, C. G. (1989). Modality effects and the structure of short-term verbal memory. Memory and Cognition, 17, 398-422.

Peterson, L., \& Peterson, M. (1959). Short-term retention of individual verbal items. Journal of Experimental Psychology, 58, 193-198. doi:10.1037/h0049234

Pillay, H. K., \& Wilss, L. A. (1996). Computer assisted instruction and individual cognitive style preferences in learning: Does it matter? Australian Educational Computing, 11(2), 28-33.

Riding, R. \& Grimley, M. (1999). Cognitive style, gender and learning from multimedia materials in 11-year-old children. British Journal of Educational Technology, 30, 43-56. doi: 10.1111/1467-8535.00089

Rogowsky, B. A., Calhoun, B. M., \& Tallal, P. (2015). Matching learning style to instructional method: Effects on comprehension. Journal of Educational Psychology, 107(1), 64-78.

Romanelli, F., Bird, E., \& Ryan, M. (2009). Learning styles: A review of theory, application, and best practices. American Journal of Pharmaceutical Education, 73(1), 9. doi:10.5688/aj730109

Sarikhani, R., \& Zare, M. (2015). The relationship between learning and extraneous cognitive load in multimedia instruction method in the chemistry course. Technical Journal of Engineering and Applied Sciences, 5, 418-421.

Schmeck, A., Opfermann, M., van Gog, T., Paas, F., \& Leutner, D. (2014). Measuring cognitive load with subjective rating scales during problem solving: Differences 
between immediate and delayed ratings. Instructional Science, 43(1), 93-114. doi:10.1007/s11251-014-9328-3

Sweller, J. (1989). Cognitive technology: Some procedures for facilitating learning and problem solving in mathematics and science. Journal of Educational Psychology, 81 (4), 457-466.

Sweller, J. (2004). Instructional design consequences of an analogy between evolution by natural selection and human cognitive architecture. Instructional Science, 32, 9-31. doi:10.1023/b:truc.0000021808.72598.4d

Sweller, J. (2005). The redundancy principle in multimedia learning. In R. E. Mayer (Eds.), The Cambridge handbook of multimedia learning (159-167). New York: Cambridge University Press.

Sweller, J. (2010). Element interactivity and intrinsic, extraneous, and germane cognitive load. Educational Psychology Review, 22(2), 123-138.

Sweller, J., \& Chandler, P. (1994). Why some material is difficult to learn. Cognition and Instruction, 12, 185-233. doi:10.1207/s1532690xci1203_1

Sweller, J. (2015). Working Memory, long term memory, and instructional design. Journal of Applied Research in Memory and Cognition. http://dx.doi.org/10.1016/j.jarmac.2015.12.002

Thakur, D., Vij, A. K., \& Shri, C. (2017). Matching Teaching Pedagogy with Learning Styles of Students-Insights through Literature Review. International Journal of Emerging Research in Management and Technology, 6(5), 38-43.

Tseng, J. C. R., Chu, H.-C., Hwang, G.-J., \& Tsai, C.-C. (2008). Development of an adaptive learning system with two sources of personalization information. Computers \& Education, 51(2), 776-786. doi:10.1016/j.compedu.2007.08.002

Veenman, M. V. J., Prins, F. J., \& Verheij, J. (2003). Learning styles: Self-reports versus thinking-aloud measures. British Journal of Educational Psychology, 73(3), 357-372. doi:10.1348/000709903322275885

Ward, M., \& Sweller, J. (1990). Structuring effective worked examples. Cognition and Instruction, 7(1), 1-39.

Wehrwein, E. A., Lujan, H. L., \& DiCarlo, S. E. (2007). Gender differences in learning style preferences among undergraduate physiology students. AJP: Advances in Physiology Education, 31(2), 153-157. doi:10.1152/advan.00060.2006

Wilcox, R. (2012). Modern statistics for the social and behavioral sciences: A practical introduction. Boca Raton, FL: CRC Press. 